\title{
Dominance and Affiliation: Paradigms in Conflict
}

\author{
MARYANN AYIM The University of Western Ontario
}

Key Words: Dominance, competition, affiliativeness, gender patterns in conversations.

Abstract: Gender patterns in speech styles provide us with models of both the dominant confrontational style (male) and the affiliative nurturant style (female). In this paper, I argue that dominant confrontational styles are seriously problematic, in speech as well as in behaviour generally, whereas affiliative nurturant styles offer us a model which can be generalized without contradiction. I distinguish confrontation from competition and address briefly how our clas srooms might be used to teach affiliative nurturant styles of talking and living.

For six months, I lived in northern California in one of the geographically loveliest spots on the earth. In the foreground were large rolling hills on which deer could be spotted occasionally and the room in which I worked looked out on a brook and small waterfall. Shrubs with red and pink and purple flowers divided the traffic lanes of city streets and even the superhighways were bordered by brilliantly coloured floral ground cover. I was a three hour drive away from what many would agree is the best downhill skiing in the world (Lake Tahoe) and only slightly further from the magnificent Yosemite hiking trails of the Sierra Nevadas. It approached a personal version of heaven.

Paradoxically, it was while living in the midst of all this physical loveliness that the macrocosmic perspective on the evils of aggressive confrontational behaviour were most dramatically borne home to me, for California is also one of the most violent places in the world. Not having a social network of friends and activities, watching television in the evenings held more appeal than it normally did. 1 found that the vast bulk of televised "entertainment" consisted of dramatized brutal violence and, equally worrisome, that such programs were almost indistinguishable from the local news.

Two weeks after my arrival, a thirteenyear-old girl, walking from a figure skating practice to a friend's house along one of the beautiful floral-lined streets that I extolled earlier, went missing and an intensive search has turned up no clues to her whereabouts. Around the same time, a man armed with a semiautomatic combat gun went on a rampage in a local school yard (Stockton), killing five children and injuring twentynine others as well as a teacher. The debate about possession of combat weapons and gun legislation intensified in the wake of this incident. A fourteen-year-old girl in a nearby community, upset that her father did not approve of her boyfriend, hired a thug (that same boyfriend) to execute him. The man was beaten to death with a two-by-four. A woman waiting at a bus stop was shot down by a passing motorist "just for the fun of it." Beatings and assaults of racial minorities by skinheads and gang-related killings were so commonplace as to be barely newsworthy. I have selected my examples for their dramatic effect, but the list nevertheless provides an accurate picture of current events in this community.

Surrounded by this glut of evidence testifying to the consequences of aggressive confrontational behaviour, I was jolted into rethinking my philosophy of education. At the macrocosmic level, 1 am no longer prepared to identify the teaching of critical thinking as the most important mission of education, and I am no longer even certain that education is the most compelling imperative of schooling.

I don't know whether I have grown more conservative or more radical, but $l$ am now convinced that as social institutions, 
schools need to serve social ends, and primary among these ends is the attainment of a peaceful, other-oriented, caring society. Autonomy, my summum bonum of old, now plays second fiddle to altruism in this hierarchy of ends.

These introductory remarks concern revisions which I would make in my macrocosmic picture of the role of education and schooling in society. My present task is not to defend this picture, however; I offer it for the broad background strokes it provides and against which $I$ write this particular paper. I urge that both the content and the style of critical thinking classes have focussed too much on confrontational rather than cooperative styles of learning, and that it is time we changed direction. Some discussion of the particular form which such a shift would entail for classrooms occurs towards the end of this paper.

It is important that I clarify a possible misunderstanding of my schema at the outset. I have no wish to eliminate competition or the competitive spirit from either the classroom or the real world. I do not want to turn our classrooms into nurseries and graduate suckling babies, for these could not survive in the world. Not only must our students survive the world-they must change it in crucial ways if society itself is to survive, and for this they will have to make a radical shift from an aggressive confrontational paradigm to a supportive, nurturant paradigm.

Competition will not go out with the old paradigm, however, but will be critical to the development of the new one. This point is so important to my position that I shall devote considerable time to clarifying it now. The Concise Oxford Dictionary defines "compete" as "strive for superiority in a quality" or "strive with or against another for a thing" (1982). We have here three different but related notions of competing: (1) the striving for superiority in a quality; (2) the striving with another for a thing; and (3) the striving against another for a thing. I suggest that the first two senses should not generate any form of censure from those who wish to achieve a nurturant affiliative society and that it is only this third sense which is incompatible with such ends.

To compete, in the sense of striving for superiority in a quality, is a necessary feature of our world. Even a world which devoted itself to cooperative enterprises would be competitive in this sense, insofar as its institutions would strive for superiority in their cooperative endeavors. Schools whose educational ideals were embedded in cooperative notions would seek out those teachers most highly skilled in cooperative behaviour and most highly skilled at transmitting cooperative strategies to their students. Those of us who are committed to working towards a more nurturant, affiliative, and peaceful society will have to underwrite this first sense of "compete," insofar as we shall wish, for example, to keep violent insensitive people out of positions of responsibility and keep cooperative nurturant people in these positions. Nurturant goals, like any goals, assume the worth and the necessity of striving for superiority.

To compete, in the sense of striving with another for a thing, is similarly consistent with and presupposed by such goals. As Keller and Moglen (1987) argue, competition and cooperation are not necessarily antithetical. Individuals can cooperate with one another precisely in order to compete more effectively as a group. All good team players are aware of this phenomenon. The Canadian hockey team learned the hard way the shortsightedness of individual competitiveness when it played and lost to the Russian hockey team some years ago. Between individual competitiveness and team cooperativeness is a tightrope on which each player must achieve a balance. Those of us committed to the achievement of cooperative nurturant social institutions, such as day care centres, shelters for battered women, or drop-in centres for the elderly, to mention only a few, will have to underwrite this second sense of "compete" in our struggle to procure sufficient funding.

There is a tendency to link competitiveness with selfishness, but this link is by no 
means necessary. We are all familiar with people whose ambition to outstrip others in the levels of self-sacrifice and altruism which they achieve is every bit as fierce as the more obviously self-serving ambition which drives the successful business person. As I have attempted to show, placing a high value on cooperative skills by no means rules out the use of competition as a basis for identifying those who possess greater levels of such skills and those who are more able to transmit such skills in teaching.

I suspect that competition has become a dirty concept because of the third sense, namely, striving against another for a thing. This sense does suggest the possibility of a zero-sum situation in which my winning entails your losing. Even in this case, however, opting out of the competition is not necessarily the most viable means of achieving nurturant ends. In the Karen/Harriet story, as recounted by Keller and Moglen, Karen turns down the offer of a job which she had very much wanted because her close friend Harriet had also wanted the job (1987:503). This resolution to the problem of competition is problematic for, among other reasons, its failure to promote cooperative ends; Karen may have solved the immediate problem of entering into competition with her close friend, but by withdrawing, she undercut her opportunity to help make that particular workplace more cooperative and less competitive in this third sense.

I have argued that the first two senses of "compete" are not merely compatible with but presupposed by nurturant cooperative ideals. While the third sense may conflict with these ideals, I have argued that it does not follow that such ideals are necessarily best accomplished by withdrawing from such competitions.

Those who would bring us a new world would be ill equipped indeed if they had no means of competing with the old, and I do not propose to eliminate the acquisition of competitive skills from the curriculum. What I do propose to eliminate is a notion of excellence culled from aggressive, confrontational, and outright violent models. I have argued in detail elsewhere (Ayim, 1988) that a standard picture of the ideal philosophy classroom has been greatly influenced by exactly this model, and I shall not repeat those arguments here.

My claims about competition are similar in some respects to those developed by John Wilson (1989); that is, we both believe that competition is not necessarily an evil in itself, and may in any case be unavoidable. An important difference, however, is that Wilson appears to exult in the competitive endeavor itself. Referring to an article in which R. M. Hare tore to shreds one of his own articles, Wilson recounts his initial feelings of dismay and anger, but tells us that he later "came ... actually to appreciate and enjoy the way in which this demolition job was carried out" (1989:29).

I won't pretend not to understand what Wilson is talking about here. In one such personal match which I entered, I was called a "lunatic" in print. This incident occurred ten years ago, and although my memory of the particular arguments has dimmed, my sense of delight at the feisty interchange is as vivid as it was during that evening I spent at my kitchen table ten years ago, writing my rejoinder to the response. In my case, however, I am acutely aware that it was not the fray which I enjoyed, but the winning. Unlike Wilson, I wouldn't enjoy losing, even if the battle were a magnificent one. And more to the point, were I engaged in anything but an academic battle, for example, a San Francisco street gang war, any notion of being on the losing side and enjoying the demolition job becomes ludicrous. Wilson, of course, knows the difference between a battle of words and a real battle; part of his argument is that mock battles may have a cathartic effect and keep us out of real battlefields. In addition to my general skepticism regarding catharsis arguments, I have two reservations about this position: first, the mock battle will almost definitely have the effect of both glorifying and highlighting the real battle as an 
approach to solving problems; second, it obscures the more viable but less spectacular approach to problem solving, the approach based on discussion, exchange, and possibly compromise.

What I wish to focus on now is a real-life example of two conflicting paradigms-the one centered on confrontation and control and the other centered on nurturance and affiliativeness. The phrase "centered on" is important here, for the paradigms themselves are spread over a spectrum of issues and meanings. As the reader may have noticed, in this paper I have shifted between the terms "confrontational," "dominant," and "aggressive" on the one hand and "affiliative," "nurturant," and "cooperative" on the other. The particular terms within each of these two sets of terms share partial meanings, and exemplify the paradigm. I believe that any attempt to identify the paradigms using only two contrasting terms and eliminating the others would be a move in the wrong direction. Thus, I have opted instead to retain the multiple terms, selecting the particular term which seemed the closest match for the specific aspect of the paradigm being discussed. In other words, I believe that the multiplicity of terms permits a more accurate portrayal of the shades of meaning of the paradigms than a rigid adherence to two terms would do. The paradigms emerge from gender patterns in language as well as from other aspects of human behaviour; as these observations about language provide significant illumination for my remarks, I shall pause now to provide a brief summary of them.

A wonderful passage from Why Didn't They Ask Evans? reveals Agatha Christie's keen insight into differences between the way women and men use language.

"Ring up the castle," cried Bobby to the nurse]. "Tell Lady Frances she must come back here at once."

"Oh, Mr. Jones. You can't send a message like that."

"Now look here, my dear girl," said Bobby, "don"t stand there arguing with me.
Ring up as I tell you. Tell her she's got to come here at once because I've got something very important to say to her."

Overborne, but unwilling, the nurse went. She took some liberties with Bobby's message.

If it was no inconvenience to Lady Frances, Mr. Jones wondered if she would mind coming as he had something he would like to say to her, but, of course, Lady Frances was not to put herself out in any way. (Christie, 1934:58)

Several of the gender differences in language documented by contemporary research are evident in this brief excerpt. Bobby Jones is the humble son of a poor vicar. He is co-owner of a small auto-body shop where he works as mechanic, autobody worker, and salesperson. Notice that Agatha Christie does not let the difference in rank between the working man, Bobby Jones, and Lady Frances stand in the way of Bobby's abrupt message, "Tell Lady Frances she must come back here at once." It is true that Bobby and Lady Frances are friends and that this somewhat diminishes the peremptory nature of the message. Nevertheless, this passage shows great insight on the part of Agatha Christie for it predates by some fifty years very contemporary research which shows that male patients take peremptory liberties when speaking to female physicians, for example (Kohn, 1988:66). In this contemporary research, the rank and gender differences of Bobby Jones and Lady Frances are replicated perfectly. In the brief passage quoted above, Christie captures very clearly the greater politeness of female speech patterns. By using verbs like "will," "would," "can," or "could," and by avoiding direct commands or imperatives, women's speech achieves greater politeness than men's speech (Lakoff, 1975:18-19). Whereas Bobby says, "Tell Lady Frances that she must come back here at once," the nurse says that "Mr. Jones wondered if Lady Frances would mind coming back."

Women are concerned with affiliation in their use of language and men are concerned with control. This very basic differ- 
ence in function is documented in several studies (Smith, 1985:136; Fishman, 1977:99-101; Zimmerman and West, 1975:125). Women and men operate from within different paradigms in their use of language and these paradigms are tightly integrated into other aspects of our gendercoded world. They mesh with the traditional division of labour both in the home and in the paid workforce. They mesh with the private/public distinction and its perceived match for female/male, and they mesh with the particular items that make up our understanding of what it is to be female and male.

Particular styles will be associated with particular linguistic functions. For example, rude, brusque language is unlikely to achieve affiliative goals. Hence female speech is usually perceived as more polite than male speech (Spender, 1980:356 and Smith, 1985:153). Compare the nurse to Bobby Jones in this regard. Nor is turning a deaf ear to the speaker likely to achieve great interactive strides. Studies indicate that in mixed-sex groups, women are much more likely to comment upon or question a remark made by a man, thus indicating interest, whereas men frequently respond to women by changing the topic of conversation abruptly or simply ignoring the comment in stolid silence (Fishman, 1977:99-101). Even the tag question, for example, the "isn't it" of "It's warm in this room, isn't it?" or the "shouldn't he?" of "Jones should obviously be short-listed, shouldn't he?", appears to be used for different purposes by the sexes-whereas women use it as a conversational icebreaker, men use it to intimidate and to achieve agreement with their own point of view (Adams and Ware, 1979:496).

Persistent interruption of a speaker is also unlikely to warm the cockles of her heart and heighten the interactive occurrence. Studies indicate that most of the interruptions-from 85 to 95 percent or higher-which occur in mixed-sex conversations are a result of males interrupting females (Key, 1975:130 and Zimmerman and West, 1975:116-17). To interrupt is to override the informal but nevertheless well-established rules of turn-taking which govern our ordinary language (Key, 1975:130). While persistent interruption undermines affiliative behaviour, it goes hand in hand with the maintenance of power and control as well as linguistic confrontation.

Nor is hogging the conversation conducive to establishing an atmosphere in which affiliative behaviour will flourish. It does have to do with exercising control and power, however. Again, studies indicate that men do far more of the talking than women do. They not only take more actual turns at talking, but they talk for longer periods during each turn (Spender, 1980:41-42; Zimmerman and West, 1975;118; Swacker, 1975:80). One of the most surprising aspects of the research on gender and language is the very surprise with which evidence of the greater verbosity of men is received. That men talk more than women flies in the face of the stereotype of the yappy verbose woman who chatters on and on nonstop, while the silent long-suffering man can barely get a word in edgewise.

When videotapes of classroom dynamics were shown to administrators and teachers, the subjects unanimously perceived the girls as doing more of the talking, whereas in fact the boys, who comprised a smaller proportion of the students, did far more of the talking (Sadker and Sadker, 1985:5456). The boys also talked out of turn more and shouted out answers without being asked more than the girls did, but this generally was not perceived by the subjects until it was pointed out to them (see also Spender, 1982:57).

There is a real sense in which women and men speak different languages or operate within totally different paradigms. The functional nature of women's language is defined by its success in achieving affiliative behaviour, whereas the functional nature of men's language is defined by its success in achieving confrontational exchanges and mastery. When gender- 
identified speech patterns were judged for adequacy and female patterns found deficient, this was often a function of operating within the male paradigm of confrontation and mastery. If one uses language in order to achieve control and dominance, then any behaviour which gives the other speaker an equal opportunity to speak, and which even goes so far as to enhance what that speaker says, is, by definition, counterproductive and weak. One who wishes to exert power over others does not encourage them to take equal time. One cuts them off, interrupts them, puts them in their place. On the other hand, if one's linguistic sights are set on nurturant affiliative goals, one will be solicitous of others' comfort, and this solicitude will find expression in both verbal and nonverbal behaviour (Smith, 1985:156). If affiliative purposes govern our use of language, then brusque bullying styles must be perceived as weak and inadequate. The fact that the literature on gender differences in language has more or less consistently judged female rather than male patterns to be weak, uncertain, and inadequate (Key, 1975:76 and Lakoff, 1975:15) is an indication that the judgments have been made from within the male paradigm.

I believe it to be self-evident that speech or behaviour patterns built around domination and control become non-functional or self-defeating when generalized. If everyone consistently responded to other people's verbal contributions by ignoring the remark or changing the subject, then we would be hard-pressed indeed to keep a conversation going. If instead of listening to what people had to say, we automatically interrupted them, it is hard to imagine why they would even want to talk to us. If these conversational tactics were generalized, there could be no conversation - we would end up instead with the linguistic equivalent of the final scene in a Shakespearian tragedy, where all the major players, having contrived to stab one another through the heart, languish in terminal soliloquy.

Neither casual conversation nor philosophical dialogue nor hope for the planet can survive the generalization of such ploys; what we need are the skills of Mrs. Fairford as described by Edith Wharton.

With Mrs. Fairford conversation seemed to be a concert and not a solo. She kept drawing in the others, giving each a turn, beating time for them with her smile, and somehow harmonizing and linking together what they said. (Wharton, 1913:34)

Nor does this claim depend in any way on the empirical studies which have linked such styles to the female populace. Mrs. Fairford's gender is totally irrelevant (although not perhaps to Mr. Fairford), but her skills are crucial to sustaining dialogue, particularly over the rough patches. It wouldn't matter whether the styles in question were indigenous to the Columbian ground squirrel or the tropical wall gecko, provided that they fostered the sort of symphony of voices and points of view that Mrs. Fairford achieved. Although I cannot deny that it pleases me to locate the superior style in the empirically identified speech of women, the important issue is not which gender has in the past utilized which particular style, but rather which styles are superior and how we incorporate these into our classrooms.

What sorts of behaviour one would applaud as desirable depends, of course, on the context in which the behaviour occurs. Consider an initial example where the agent's goal is to get someone to do something immediately, no questions asked. Perhaps there is a state of emergency, such as a life-threatening fire in a building, which the agent wishes people to vacate immediately. Domineering and controlling behaviour may well be the most likely to succeed here. Polite conversation in which one solicits and listens carefully to the other's point of view would not be advised.

Now suppose a different context in which the goal is not to clear a building, but to generate interest and discussion among a group of people about why appeal to force is a weak logical move; alternatively, the hoped-for discussion could be an under- 
standing of incendiary devices and the means of extinguishing fire caused by different elements in a class for fire-fighting students. In these contexts, the controlling paradigm is misplaced and self-defeating. By this I do not mean that I think the teacher should have no power or authority over the students; rather I mean that exactly what we want in these classrooms are conversations, in the sense that everyone is encouraged to contribute, and what they say is listened to very carefully. I realize there is nothing original in this claim. That education is best likened to and achieved through a conversation is a view at least as old as Plato.

Now consider an agent whose goals are to win an argument, to teach others how to win arguments, and to help others learn to construct, recognize, and appraise arguments. Controlling domineering behaviour may be instrumental to the first goal (although not even this is perfectly clear), but will be much less relevant to the second goal, and will have no place at all in the realization of the third. This third goal is by nature interactive, and the skills necessary for excellence are interactive skills.

It is important to realize that even with the goals of the agent clearly specified, other relevant aspects of the context have been ignored. The relationship of the agent to the participant, whether parent, teacher, peer, acquaintance, or stranger, may have an effect on the determination of the desirable behaviour. Whether or not the agent bears any special legal or moral responsibility towards the participant will be a further complicating factor emerging from the nature of the relationship. The age and reasoning level of the participant will also be relevant to identifying the desirable behaviour.

Other apparently peripheral characteristics of the agent or participant may in fact be crucial to the choice of behaviours. That a particular participant has very low selfesteem or that the agent has a marked tendency to become hostile when openly challenged by a participant will need to be taken into account when choosing how to act. Beliefs which the agent and participants hold about each other may also affect the likely success of any given behaviour; for example, the agent may believe that the participant is stupid, or that aggressive behaviour is intolerable in a female, or that assertive language is inappropriate for a child; the participant may believe that the agent's views on the issue in question are authoritative or that sexual preferences of a certain sort automatically render one an unfit instructor. That such beliefs may be false will not necessarily invalidate taking them into account when choosing behaviours and will not soften in the least their impact on the actual state of the world.

We have to begin with the recognition of other people's beliefs and feelings, even if those beliefs are as intolerable as those of the Ku Klux Klan. We can dismiss such beliefs as false and the behaviour which springs from them as morally unacceptable, but our dismissal will not end the harm which they generate. Ending the harm demands that we start by recognizing very clearly the nature of such beliefs, noting in whose heads they reside, and understanding how they shape the world. We need to know not just what other people are saying, but what they are thinking as well, a capacity attributed to women by Rousseau (1780:346-47). Whether Rousseau was right or wrong is irrelevant-the important issue is that this capacity may be the only viable means of intercepting the objectionable behaviour.

In critical thinking classrooms, we can do our share to move society away from dominant confrontational paradigms towards affiliative cooperative paradigms. It is not clear that this will result in fundamental social change, but then it is not clear that any particular educational ideology will leave its mark on society. I would hate to be asked to put money on formal schooling against prime time television as a shaper of social outlooks. Nonetheless, as responsible educators, we must choose among ideologies and do our best to implement morally preferable ideologies in our own class- 
rooms. Some people may believe that the proper stance of educators is one of pure neutrality, an eschewing of any particular ideology. I urge that any such neutrality claim is patent nonsense, and share Florence Howe's views on this issue. Howe says:

In the broadest context of that word, teaching is a political act: some person is choosing, for whatever reasons, to teach a set of values, ideas, assumptions, and pieces of information .... Education is the kind of political act that controls destinies, gives some persons hope for a particular kind of future, and deprives others even of ordinary expectations for work and achievement. (Howe, 1984:282-83.)

This paper has offered an argument for our adoption of ideology rooted in affiliative cooperative norms as opposed to dominant confrontational norms. Just how critical thinking classrooms could become milieus in which these affiliative cooperative norms are promoted is difficult to specify.

I believe it is difficult to specify because most of us who teach critical thinking classes have little personal experience and few models which will come to our assistance. I have some hesitation in sharing my own classroom approaches to this issue, not because I wish to keep them secret, but because they seem so paltry in the face of the problem. In the absence of any other clear way to proceed, I shall do exactly that, however.' I shall begin with a discussion of the students' written work and end with a discussion of classroom dynamics. In both cases, it is very clear that if affiliative cooperative norms are really to be promoted in classrooms, then they must be rewarded, which means, I believe, that students must receive grades based on their success in exemplifying these norms. With regard to the students' written work, one strategy I have found useful is to encourage the students to work in small groups. (I recommend three.) It is very much in their interests to work together cooperatively and critically; I typically have each group perform a detailed critical analysis of an argument. They submit a first draft of this critical analysis which receives a grade worth only a small proportion of their final grade. They then receive feedback from myself and exchange, anonymously, feedback with a different group of students engaged in preparing an analysis of the same argument. All groups of students are graded on the feedback they provide, where my main criterion in grading is the degree to which they have helped the critiqued group improve their analysis. All groups then prepare a revised version of their analysis, in which they must show evidence of having benefitted from the two sets of critiques. This does not mean they are required to change or "water down" their original views; one possible way of responding to the critiques is to "dig in their heels" more deeply, and show why the claims of the critiques are wisely ignored in their paper.

In terms of actual classroom dynamics, I believe the crucial element is to create an environment in which all students feel free to speak and to express their points of view. I realize that this claim is trivially obvious to most of us, but its instantiation in classrooms is not trivially easy. I have less confidence in having achieved affiliative goals even to a minimal extent in this aspect than in the written work which the students do. Nevertheless, it does seem clear that there are certain things which we should pay attention to. Not only must each student feel free to speak, but each student must seek to enhance other students" sense of freedom to speak. It is also important that the class not become so caught up in the idea of everyone speaking that the dynamics degenerate into an unstructured free-for-all. Students should be judged (and graded) not merely on whether they participate, but whether they contribute to the learning of others. Dominant confrontational interaction patterns should be identified and discussed by the class, together with alternative affiliative cooperative patterns. William Fawcett Hill's Learning Thru Discussion provides straightforward guidelines on setting up classroom discussion groups based on the practice of precise affil- 
iative cooperative techniques to promote learning.

If all educators were to promote cooperative affiliative norms over dominant confrontational ones, then we would have gone some distance towards rendering society more cooperative and affiliative. No doubt John Wilson is right that there are contexts in which it is justifiable and perhaps even necessary to go to war. What such a claim leaves unsaid is that in addition to the roads that lead to war, there are also roads that lead to peace if we could but recognize them. The skills we have honed and glorified, however, are literally or metaphorically linked to doing battle. With all of our technology and our expertise, we have created multi-lane superhighways that lead to the battleground, but the roads to peace are more like ungroomed trails, overgrown, boulder-strewn, and frequently unblazed. We need to concentrate our energy now, as much in critical thinking classrooms as anywhere, on grooming these trails, and developing the capacities that will enable us to travel them in safety and hope. Perhaps if the operating paradigms of excellence reflected nurturance and affiliation rather than dominance and confrontation, and if competition were made to serve the end of achieving a more nurturant affiliative society rather than pursued for its own sake, we would have fewer people whose selfhood found expression in turning semiautomatic combat weapons on schoolyards filled with children.

\section{Notes}

1 The strategies which I have incorporated into my classroom owe much to what $I$ have learned from others. In this regard, I am particularly indebted to Barbara Houston and Kate Morgan. Carol Agocs provided me with very helpful suggestions regarding her own classroom strategies.

\section{Bibliography}

Adams, Karen L. and Ware, Norma C. "Sexism and the English Language: The Linguistic Implications of Being a Woman", in Woman: A Feminist Perspective (2nd ed.), 487-504. Ed. Jo Freeman. Palo Alto, CA: Mayfield, 1979.

Ayim, Maryann. "Violence and Domination as Metaphors in Academic Discourse", in Selected lssues in Logic and Communication, 184-95. Ed. Trudy Govier. Belmont, CA: Wadsworth, 1988.

Christie, Agatha. Why Didn't They Ask Evans? London: The Crime Club, 1934.

The Concise Oxford Dictionary of Current English. Ed. J. B. Sykes. Oxford: Clarendon Press, 1982.

Fishman, Pamela "Interactional Shitwork", Heresies: A Feminist Publication on Arts and Politics, 2 (May 1977), 99-101.

Hill, William Fawcett. Learning Thru Discussion.
Intro. Herbert A. Thalen. Newbury Park, CA: Sage, 1962.

Howe, Florence. "Feminist Scholarship: The Extent of the Revolution (1981-1982)", in Myth of Coeducation; Selected Essays, 1964 . 1983, 270-84. Ed. Florence Howe. Bloomington, IN: Indiana University Press, 1984.

Keller, Evelyn Fox and Moglen, Helene. "Competition and Feminism: Conflicts for Academic Women", Signs: Journal of Women in Culture and Society, Vol. 12, No. 3 (Spring 1987), 493-511.

Key, Mary Ritchie. Male/Female Language, with a Comprehensive Bibliography. Metuchen, NJ: Scarecrow Press, 1975.

Kohn, Alfie. "Girl Talk, Guy Talk: Do Men and Women Really Have Distinctive Conversational Styles?", Psychology Today (February 1988), 65-67. 
Lakoff, Robin. Language and Women's Place. New York; Harper \& Row, 1975.

Rousseau, Jean Jacques. Emile. Trans. Barbara Foxley. London: J.M. Dent \& Sons, 1780. (First published in this edition in 1911.)

Sadker, Myra and Sadker, David. "Sexism in the Schoolroom of the " $80 \mathrm{~s}^{\text {", Psychology Today }}$ (March 1985), 54-57.

Smith, Philip M. Language, the Sexes and Society. Oxford: Basil Blackwel1, 1985.

Spender, Dale. Man Made Language. London: Routledge \& Kegan Paul, 1980.

Invisible Women: The Schooling Scandal. London: Writers and Readers Publishing Cooperative Society, 1982.

Swacker, Marjorie. "The Sex of the Speaker as a Sociolinguistic Variable", in Language and Sex: Difference and Dominance, 76-89. Eds. Barrie Thorne and Nancy Henley. Series in
Sociolinguistics, ed. Roger W. Shuy. Rowley, MA: Newbury House Publishers, 1975.

Wharton, Edith. The Custom of the Country. New York: Charles Scribner's Sons, 1913.

Wilson, John. "Competition", Journal of Moral Education, Vol, 18, No. 1 (January 1989), 26-31.

Zimmerman, D.H. and West, Candace. "Sex Roles, Interruptions and Silences in Conversation", in Language and Sex: Difference and Dominance, 105-29. Eds. Barrie Thorne and Nancy Henley. Series in Sociolinguistics, ed. Roger W. Shuy. Rowley, MA: Newbury House Publishers, 1975.

MARYANN AYIM

FACULTY OF EDUCATION

THE UNIVERSITY OF WESTERN ONTARIO

LONDON, ONTARIONOG /G7 